Research Article

\title{
Prediction of Unconfined Compression Strength for Saline-Alkaline Soils Mixed with Cement and Wheat Straw
}

\author{
Guoqi Xing $\mathbb{D}^{D}$, Changjiang Liu $(\mathbb{D}$, Wei Xuan $(\mathbb{D}$, Yueyue Pan, Bing Zhang, and Yue Zhao \\ College of Architectural Engineering, Weifang University, Weifang, Shandong, China \\ Correspondence should be addressed to Guoqi Xing; xgq1105@163.com
}

Received 22 January 2020; Revised 27 March 2020; Accepted 3 April 2020; Published 21 April 2020

Academic Editor: Akbar Heidarzadeh

Copyright (c) 2020 Guoqi Xing et al. This is an open access article distributed under the Creative Commons Attribution License, which permits unrestricted use, distribution, and reproduction in any medium, provided the original work is properly cited.

\begin{abstract}
A series of unconfined compression tests were performed to investigate the influence of wheat straws on the unconfined compression strength for saline-alkaline soils and saline-alkaline soils mixed with cement. In unconfined compression tests, 20 groups of soil specimens were prepared at five different percentages of wheat straws content (i.e., $0.0 \%, 0.1 \%, 0.15 \%, 0.2 \%$, and $0.25 \%$ by weight of saline-alkaline soils) and four different percentages of cement content (i.e., $0 \%, 3 \%, 6 \%$, and $9 \%$ by weight of saline-alkaline soils), and unconfined compression tests were carried out after 3-, 7-, 14-, 28-, and 56-day curing periods. Test results indicated that the inclusion of wheat straws within saline-alkaline soils and saline-alkaline soils mixed with cement leads to an increase in the unconfined compressive strength of specimens and also changed the brittle behavior to a more ductile one for specimens. In addition, based on the results from unconfined compression tests, a formula for predicting the unconfined compression strength of specimens related to cement content, wheat straw content, curing periods, etc., was determined, and comparing with the results from unconfined compression tests, it had higher precision in predicting the unconfined compression strength of specimens.
\end{abstract}

\section{Introduction}

Due to many advantages of synthetic fibre, such as high strength and fairly good corrosion resistance, it is widely used in the reinforcement of weak or soft soil, and some researchers had studied the mechanical properties of the soil mixed with synthetic fibre [1-5]. Now, the applied technology for the soil reinforced with synthetic fibre is widely used in geotechnical engineering. In addition, natural fibre, including plant fibre such as wheat straw, rice straw, bamboo, and ditch reed, also attracts general attention due to the advantages of easy degradation, lower cost, being environment-friendly, and so forth. Some researchers had also carried out feasibility study on the soil reinforced with nature fibre [6-8], and the results showed that the strength of soil could be effectively improved by adding natural fibre [9-12].

Saline-alkaline soils are widely existent in west coast of Bohai Bay and southeast coast in China. The salt content is greater than $0.3 \%$ in saline-alkaline soils, which can make the subgrade expanded. Moreover, the saline-alkaline soils can also make the pavement collapse. Therefore, the salinealkaline soils cannot directly be used as roadbed filling and then cement or lime is often used in reinforcing the salinealkaline soils. In order to apply saline-alkaline soils to the geotechnical engineering, some researchers had already investigated the mechanical property of saline-alkaline soils reinforced with cement or lime [13-15].

In northern China, a large number of wheat straws are burned or piled up on the open-air, causing environmental pollution. Wheat straws used as reinforced materials are different from rigid materials, such as soil nailing and anchor bar, and flexible materials, such as geotextile, in mechanical properties. The main advantage of wheat straws is that they are locally available and very cheap. If wheat straws are used in soil reinforcement, they are biodegradable and thus do not create disposal problems in the environment. Wei et al. [16] explored the tensility of wheat straw based on test method. In addition, some researchers had already applied the wheat straws as reinforced material 
to soft soil or saline-alkaline soils [17-22]. However, up to now, the theories for the soil reinforced with wheat straws are still in primary stage and should be further studied.

Therefore, in this paper, the effect of wheat straws on the saline-alkaline soils is further studied, supplementing the data available in the literature on the behavior of fibrereinforced soil. Firstly, a series of unconfined compression tests are carried out to explore the effect of wheat straws on saline-alkaline soils. Secondly, based on the data obtained from unconfined compression tests, a formula for predicting the unconfined compression strength of salinealkaline soils mixed with cement and wheat straws is derived accurately.

\section{Materials and Experimental Program}

2.1. Materials. Saline-alkaline soils samples used in the tests are obtained from the west coast of Bohai Bay, China. The microstructure for saline-alkaline soils obtained from SEM test is shown in Figure 1, showing the flocculated structure in saline-alkaline soils. In order to mould the saline-alkaline soils in the laboratory, firstly they are dried in air and then broken into pieces. The physical properties and ion content for saline-alkaline soils are listed in Tables 1 and 2, respectively. As shown in Table 1, for the saline-alkaline soils used in test, they are silty clay based on the classification of the soil [23]. As can be seen from Table 2, the content for $\mathrm{CO}_{3}{ }^{-2}$ and $\mathrm{HCO}^{3-}$ in $1000 \mathrm{~g}$ soils is $0.382 \mathrm{mmol} / \mathrm{kg}$, which is greater than $0.3 \mathrm{mmol} / \mathrm{kg}$ (JTG D30-2015 [24], national criterion for highway subgrade in China), and so the soil is called saline-alkaline soil. In addition, the ordinary Portland cement is used as the reinforcement material and the chemical content and physical properties for ordinary Portland cement are listed in Table 3.

The wheat straws used in test are obtained from Hanting District, China. Before wheat straws are mixed into soils, they should be split into strips, as shown in Figure 2. In Figure 2, the mean width and mean length for the strips are about $1.5 \mathrm{~mm}$ and about $10 \mathrm{~mm}$, respectively. The cross section of wheat straw is shown in Figure 3, showing that the fibre tissues are loose and suitable for humectation, diffusion, and permeation of liquid. In order to prevent wheat straws from decay in saline-alkaline soils, they should be soaked in limewater with $0.4 \%$ lime by weight of water for $24 \mathrm{~h}$ and then are dried in air [20].

2.2. Specimen Preparation. In unconfined compressive test, specimens with $39.1 \mathrm{~mm}$ diameter and $80 \mathrm{~mm}$ height are used, as shown in Figure 4. In this paper, the content of wheat straw and cement is defined as

$$
\begin{gathered}
W_{\mathrm{w}}=\frac{T_{\mathrm{w}}}{T}, \\
W_{\mathrm{c}}=\frac{T_{\mathrm{c}}}{T},
\end{gathered}
$$

where $T_{\mathrm{w}}$ is the weight of wheat straw, $T_{c}$ is the weight of cement, and $T$ is the weight of air-dried saline-alkaline soils. In test, the value of $W_{\mathrm{c}}$ is adopted as $0,0.03,0.06$, and 0.09

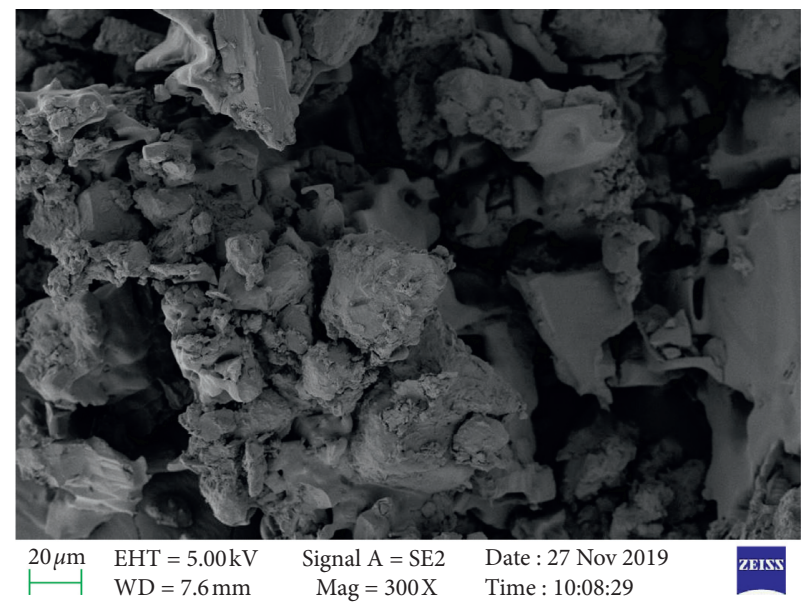

Figure 1: Microstructure of saline-alkaline soils.

and $W_{\mathrm{w}}$ is adopted as $0,0.001,0.0015,0.002$, and 0.0025 . Based on the values of $W_{\mathrm{w}}, W_{\mathrm{c}}$, and $T$, the required weight of wheat straw and cement can be calculated using equations (1) and (2).

Before mixtures are poured into mould, the inside of the mould should be coated with lubricant, which can reduce the fracture of specimens during removal. In preparing the specimens, the mixtures of saline-alkaline soils, cement, and wheat straw should be divided into three equal portions and then each portion pours into the mould to be compacted until reaching maximum dry density with optimum moisture content. Between each compression layer, the surface of compression layer should be scoured, providing reasonable bonding between compression layers. In addition, if cement and wheat straw are not used in specimens, air-dried salinealkaline soils are mixed with water based on optimum moisture content. If cement is used only in specimens, required water is first poured into air-dried saline-alkaline soils, considering quick hydration of cement, and then cement is added to moist saline-alkaline soils. If wheat straws are used only in specimens, they are firstly added to air-dried saline-alkaline soils to achieve uniform mixtures, and then required water is added to mixture of wheat straws and saline-alkaline soils. If cement and wheat straws are all used in specimens, moist mixtures of wheat straws and salinealkaline soils are firstly prepared, as described above, and then cement is added to the moist mixture. At each stage of mixing mentioned above, homogeneous mixtures are prepared manually. After all specimens are compacted in mould, they should be wrapped with plastic membrane and then placed in curing chamber for $3,7,14,28$, and 56 days, respectively.

In this study, 20 groups of specimens mixed with different cement content and wheat straw content are prepared for the unconfined compression tests (GB/T 50123-1999 [25], which is the national criterion for geotechnical tests in China). In order to ensure the repeatability of experiments, verification tests should also be carried out, and therefore each group should include 3 specimens. The details of different cement and wheat straw content are shown in Table 4. Moreover, for the specimens used in tests, they 
TABLe 1: Basic mechanical properties for saline-alkaline soils.

\begin{tabular}{|c|c|c|c|c|c|c|c|c|}
\hline \multirow[b]{2}{*}{$\begin{array}{l}\text { Specific } \\
\text { gravity } G_{\mathrm{s}}\end{array}$} & \multicolumn{3}{|c|}{ Consistency index } & \multicolumn{2}{|c|}{ Compaction test } & \multicolumn{3}{|c|}{ Grain content $/ \%$} \\
\hline & $\begin{array}{l}\text { Liquid limit } \\
w_{\mathrm{L}}(\%)\end{array}$ & $\begin{array}{c}\text { Plastic limit } \\
w_{\mathrm{p}}(\%)\end{array}$ & $\begin{array}{l}\text { Plastic } \\
\text { index } I_{\mathrm{P}}\end{array}$ & $\begin{array}{c}\text { Maximum dry } \\
\text { density } \rho_{\mathrm{d}}\left(\mathrm{g} \cdot \mathrm{cm}^{-3}\right)\end{array}$ & $\begin{array}{l}\text { Optimum water } \\
\text { content } s(\%)\end{array}$ & $\begin{array}{c}0.074 \sim 0.038 \\
(\mathrm{~mm})\end{array}$ & $\begin{array}{c}0.038 \sim 0.008 \\
(\mathrm{~mm})\end{array}$ & $\begin{array}{c}<0.008 \\
(\mathrm{~mm})\end{array}$ \\
\hline 2.71 & 32.5 & 16.9 & 15.6 & 1.85 & 16.8 & 22.5 & 57.3 & 21.1 \\
\hline
\end{tabular}

TABLE 2: Ion content in saline-alkaline soils $g$.

\begin{tabular}{lcccccccc}
\hline $\mathrm{CO}_{3}{ }^{-2}$ & $\mathrm{HCO}_{3}{ }^{-}$ & $\mathrm{CI}^{-}$ & $\mathrm{SO}_{4}{ }^{2-}$ & $\mathrm{Ca}^{2+}$ & $\mathrm{Mg}^{2+}$ & $\mathrm{K}^{+}+\mathrm{Na}^{+}$ & $\mathrm{PH}$ value & Content of soluble salt \\
\hline 0.019 & 0.171 & 18.011 & 0.871 & 0.369 & 0.761 & 9.931 & 7.72 & 33.2 \\
\hline
\end{tabular}

${ }^{*}$ The ion content is the ion mass in $1000 \mathrm{~g}$ saline-alkaline soils.

Table 3: Chemical content and physical properties of ordinary Portland cement.

\begin{tabular}{lcccccccc}
\hline $\mathrm{SiO}_{2}$ & $\mathrm{Al}_{2} \mathrm{O}_{3}$ & $\mathrm{Fe}_{2} \mathrm{O}_{3}$ & $\mathrm{CaO}$ & $\mathrm{MgO}$ & $\mathrm{SO}_{3}$ & LOI & Specific surface & Compressive strength (28 days) \\
\hline $22.3 \%$ & $4.6 \%$ & $3.6 \%$ & 65.3 & $2.9 \%$ & $3.8 \%$ & 1.7 & $373 \mathrm{~m}^{2} / \mathrm{kg}$ & $44.8 \mathrm{MPa}$ \\
\hline
\end{tabular}

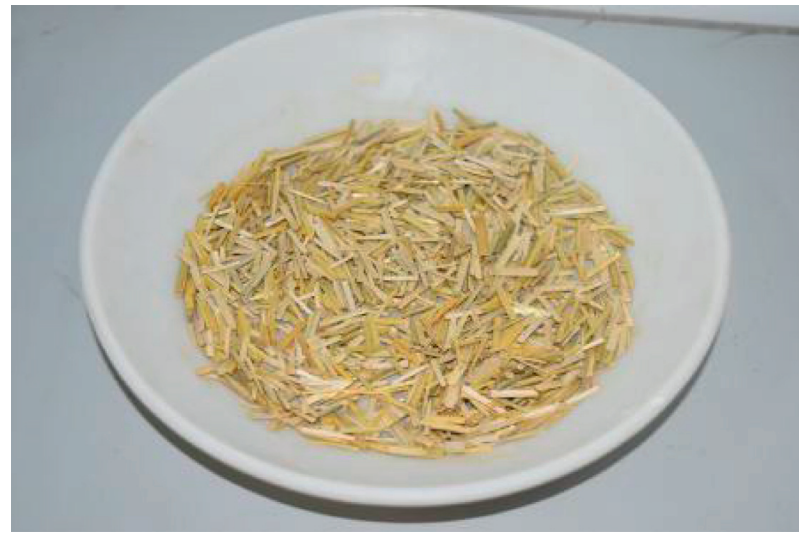

Figure 2: Wheat straws used in test.

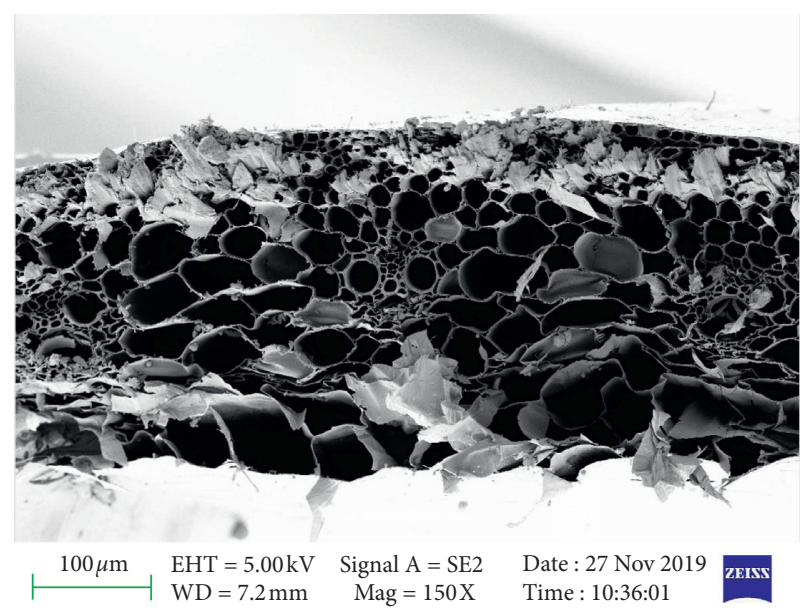

FIgure 3: Cross section of wheat straw.

should be in the state of maximum density, which can be obtained from compaction tests. Table 4 also shows the optimum moisture content for each group.

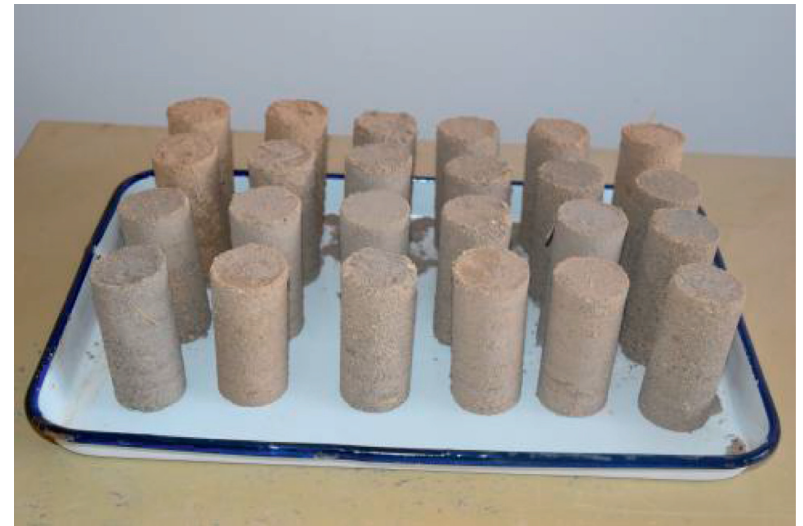

FIGURE 4: Specimens for unconfined compressive test.

TABLE 4: Cement and wheat straw content and optimum moisture content in specimens.

\begin{tabular}{lccc}
\hline $\begin{array}{l}\text { Specimen } \\
\text { no. }\end{array}$ & $\begin{array}{c}\text { Cement } \\
\text { content (\%) }\end{array}$ & $\begin{array}{c}\text { Wheat straw } \\
\text { content }(\%)\end{array}$ & $\begin{array}{c}\text { Optimum moisture } \\
\text { content }(\%)\end{array}$ \\
\hline S & 0 & 0 & 12.7 \\
W 1 & 0 & 0.10 & 12.9 \\
W 2 & 0 & 0.15 & 12.9 \\
W 3 & 0 & 0.20 & 13.1 \\
W 4 & 0 & 0.25 & 13.1 \\
C 1 & 3 & 0 & 13.0 \\
C 2 & 6 & 0 & 13.5 \\
C 3 & 9 & 0 & 13.9 \\
CW 1 & 3 & 0.10 & 13.1 \\
CW 2 & 3 & 0.15 & 13.1 \\
CW 3 & 3 & 0.20 & 13.3 \\
CW 4 & 3 & 0.25 & 13.3 \\
CW 5 & 6 & 0.10 & 13.8 \\
CW 6 & 6 & 0.15 & 13.8 \\
CW 7 & 6 & 0.20 & 14.1 \\
CW 8 & 6 & 0.25 & 14.1 \\
CW 9 & 9 & 0.10 & 14.3 \\
CW 10 & 9 & 0.15 & 14.3 \\
CW 11 & 9 & 0.20 & 14.5 \\
CW 12 & 9 & 0.25 & 14.5 \\
\hline
\end{tabular}


2.3. Unconfined Compression Tests. In order to obtain unconfined compression strength of specimens, conventional unconfined compression apparatus is used in test, as shown in Figure 5. In the unconfined compression test, axial force and corresponding displacement can be obtained automatically with multichannel real-time record system. In addition, unconfined compression tests are carried out at the last day of curing period for specimens. For the conventional unconfined compression apparatus used in test, the loading rate is set to be $2.4 \mathrm{~mm} / \mathrm{min}$ until specimens failed.

\section{Results and Discussions}

3.1. Effect of Wheat Straws on Unconfined Compressive Strength of Specimens. In this paper, based on the results from unconfined compressive tests on specimens mixed with cement and wheat straws after curing for 14 days, the stress-strain curves are obtained, as shown in Figures 6(a)6(c). As can be seen from Figure 6(a), with increasing wheat straw content, unconfined compressive strength of specimens also increases. However, further increase of wheat straw content does not significantly improve the peak axial stress. Furthermore, specimens mixed with increasing wheat straw content exhibit more ductile behavior than that not mixed with wheat straws. Figure 6(b) shows the influence of cement content on unconfined compressive strength of specimens. As can be seen from Figure 6(b), increasing cement content can improve the peak axial stress of specimens and meanwhile exhibit more brittle behavior than that not mixed with cement. Figure 6(c) shows the influence of wheat straw content on unconfined compressive strength of specimens mixed with cement. As can be seen from Figure 6(c), when the cement content is constant in specimens, the influence of increasing wheat straw content on unconfined compressive strength of specimens is similar to that in Figure 6(a).

The influence of wheat straw content on unconfined compressive strength of specimens mixed with different cement content after curing for 14 days is shown in Figure 7. As can be seen from Figure 7, not only for cemented specimens but also for uncemented specimens, the added wheat straws can increase unconfined compressive strength of specimens. As shown in Figure 7 , after $0.1 \%$ wheat straws were added, unconfined compressive strength of specimens reinforced with $3 \%, 6 \%$, and $9 \%$ cement content increases from 0.18 to $0.22 \mathrm{MPa}$, from 0.36 to $0.40 \mathrm{MPa}$, and from 0.51 to $0.53 \mathrm{MPa}$, respectively, showing that added $0.1 \%$ wheat straws content has little effect on the improvement of unconfined compressive strength of specimens. However, after $0.25 \%$ wheat straws content is added, unconfined compressive strength of specimens reinforced with $3 \%, 6 \%$, and $9 \%$ cement content increases from 0.19 to $0.38 \mathrm{MPa}$, from 0.36 to $0.52 \mathrm{MPa}$, and from 0.49 to $0.58 \mathrm{MPa}$, respectively.

The influence of curing periods on unconfined compressive strength of specimens mixed with $3 \%$ cement content and $0.1 \%$ wheat straw content is shown in Figure 8. As can be seen from Figure 8, unconfined compressive strength of specimens increases with curing periods. In addition, when curing periods are less than 14 days, the

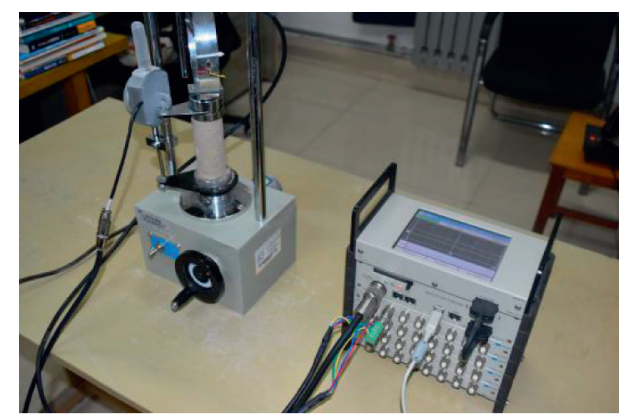

FIGURE 5: Unconfined compression apparatus.

failure of specimens exhibits the ductile behavior. However, when curing periods are greater than 14 days, the brittle behavior of failure of specimens becomes more and more obvious.

3.2. Effect of Wheat Straw Content on Failure Mechanism of Specimens. In this section, the specimens after curing for 28 days are used in unconfined compressive strength test. Figures 9(a)-9(e) show the failure of specimens only mixed with wheat straws. As can be seen from Figure 9(a), when wheat straws are not added to specimen, the failure occurs mainly on the bottom of specimens, showing the shear failure mode. When the wheat straw content is $0.10 \%$ by weight, the failure also occurs mainly on the bottom of specimens; however, the shear plane does not form, as shown in Figure 9(b). When the wheat straw content is increased to $0.15 \%$ by weight, a large shear plane forms, which extends to the top of specimens, as shown in Figure 9(c). As can be seen from Figure 9(d), when the wheat straw content is increased to $0.20 \%$ by weight, there are two failure modes in specimens: one shear failure and another bottom failure of specimens. When the wheat straw content is increased to $0.25 \%$ by weight, the bottom failure in specimens only occurs and shear plane does not form, as shown in Figure 9(e).

Figures $10(\mathrm{a})-10(\mathrm{e})$ show the failure of specimens mixed with different wheat straws content and $6 \%$ cement content. When wheat straws are not added in the specimens, the shear plane failure is mainly exhibited, which also shows the brittle behavior of specimens, as shown in Figure 10(a). However, when wheat straws are added in the specimens and the wheat straw content reaches $0.10 \%$ and $0.15 \%$ by weight, a large shear plane forms in specimens, as shown in Figures 10(b) and $10(\mathrm{c})$. As can be seen from Figure 10(d), when the wheat straw content is $0.20 \%$ by weight, only the bottom failure of specimens is shown and shear plane does not form. However, the top failure of specimens occurs when the wheat straw content reaches $0.25 \%$ by weight and also shear plane does not form in specimens, as shown in Figure 10(e).

Based on the results of unconfined compressive strength tests on specimens mixed with $3 \%$ cement content and $0.1 \%$ wheat straw content, the effect of curing periods on the failure of specimens can be obtained, as shown in Figures 11(a)-11(e). As can be seen from Figures 11(a) and 11(b), when the curing period is less than 7 days, the failure 


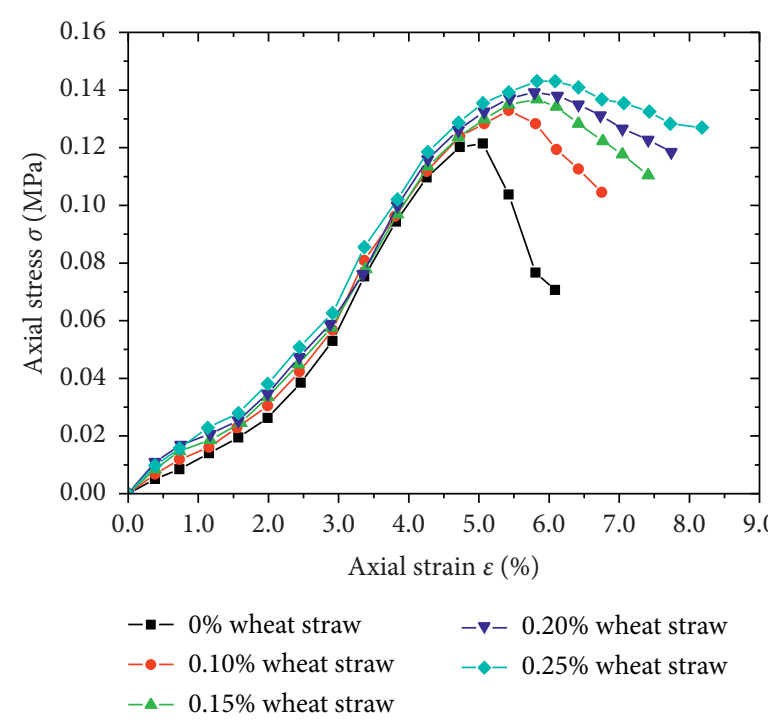

(a)

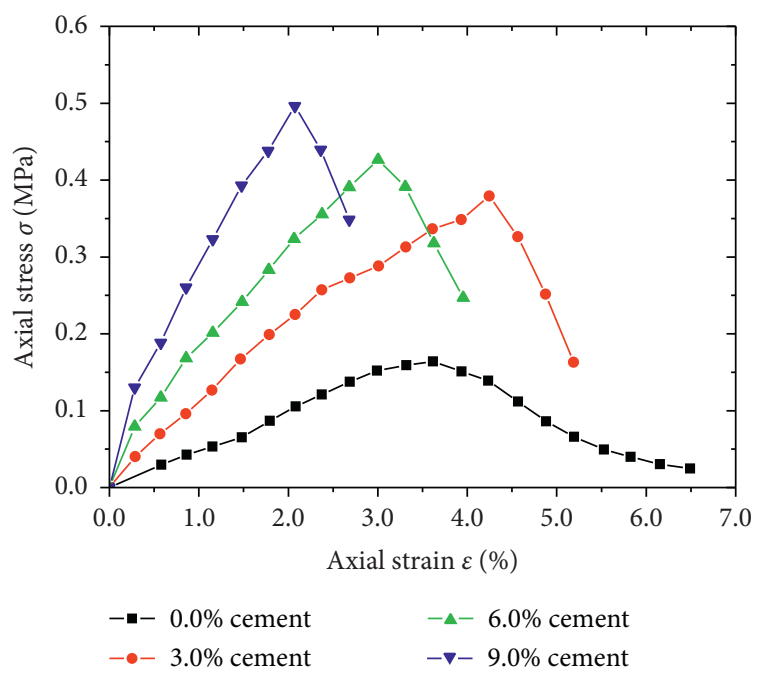

(b)

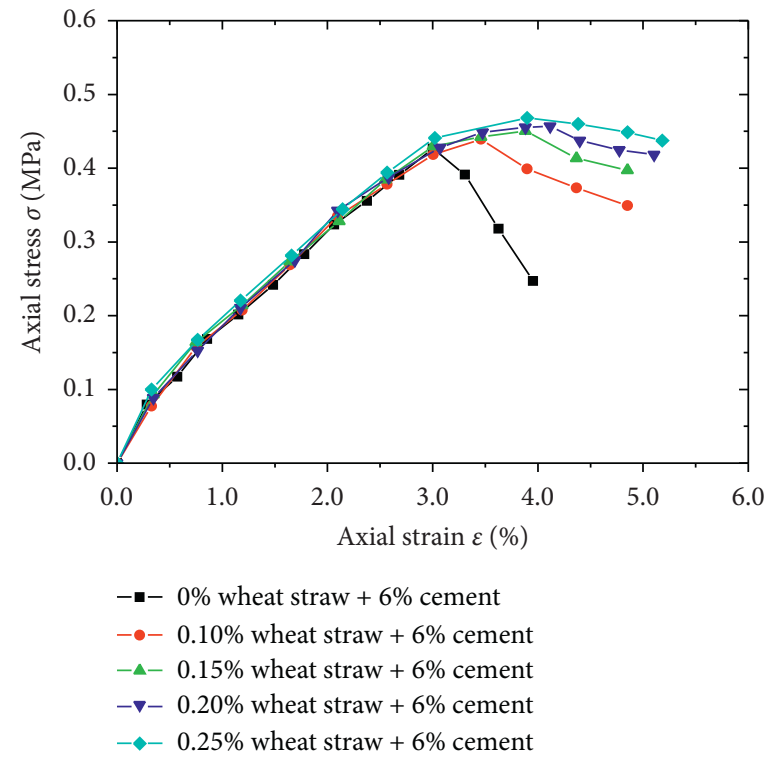

(c)

FIGURE 6: Stress-strain curves of specimens after 14-day curing period. (a) Specimens mixed with different wheat straw content. (b) Specimens mixed with different cement content. (c) Specimens mixed with $6 \%$ cement content and different wheat straw content.

of the bottom of specimens occurs and it does not obviously exhibit the shear plane. When the curing period is 14 days, there are two simultaneous failure modes in specimens, as shown in Figure 11(c). However, as can be seen from Figures 11(d) and 11(e), when the curing period is greater than 14 days, only shear plane failure occurs in specimens. During the unconfined compressive strength tests, we also find that the increasing of curing periods can improve the brittle behavior of specimens and the trend for influence of curing periods on the brittle behavior of specimens is similar to that shown in Figure 8. Specimens Mixed with Wheat Straws and Cement. As discussed above, the factors affecting unconfined compressive strength of specimens include wheat straw content, cement content, and curing periods. In this section, a formula that can predict unconfined compressive strength of specimens is put forward based on the results from unconfined compressive strength test on saline-alkaline soils mixed with wheat straws and cement. Figures 12(a)-12(d) show the increasing of unconfined compressive strength of specimens with curing periods.

As can be seen from Figures 12(a)-12(d), when the specimens have the same cement content, unconfined compressive strength of specimen increases with increasing wheat straw content. Based on the data from Figures 12(a)12(d), the curve fitting for the relationship between curing period and unconfined compressive strength of specimens 


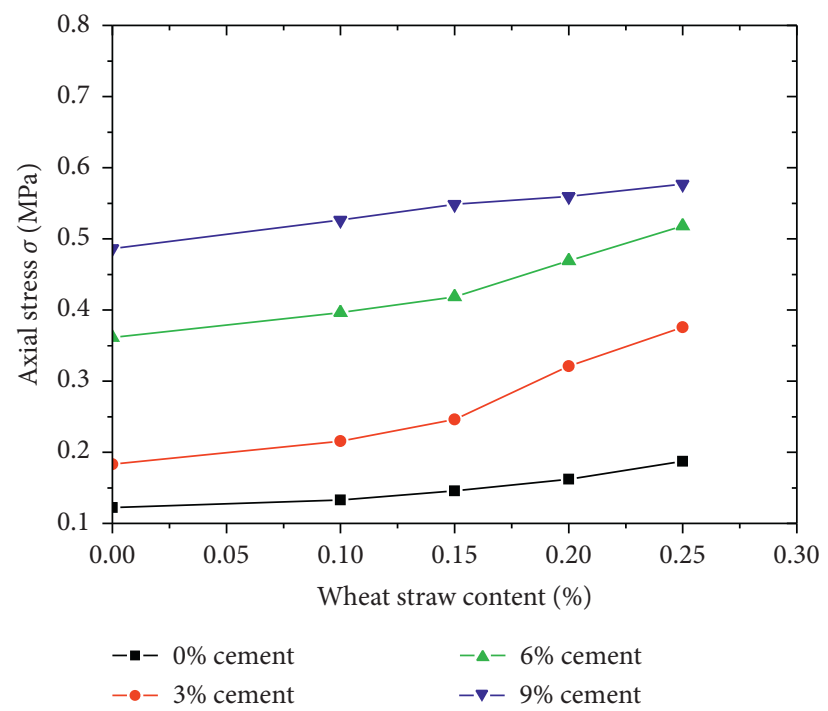

Figure 7: Relationship between wheat straw content and unconfined compressive strength after curing for 14 days.

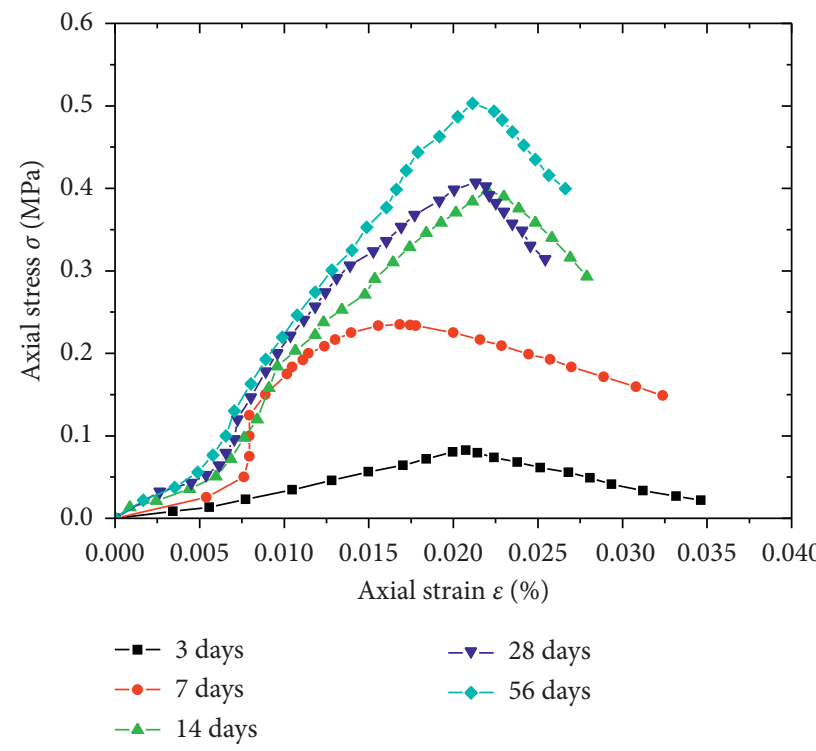

FIGURE 8: Influence of curing periods on unconfined compressive strength of specimens.

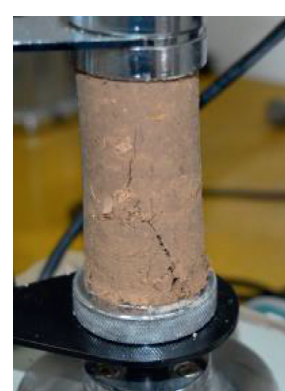

(a)

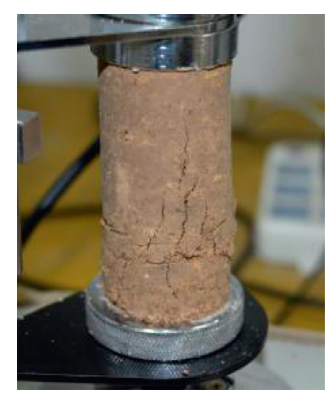

(b)

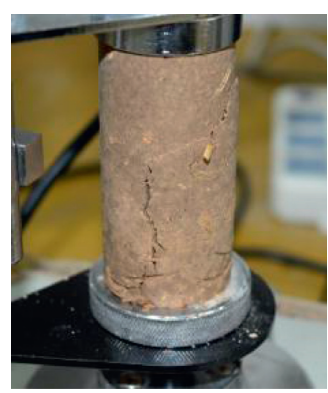

(c)

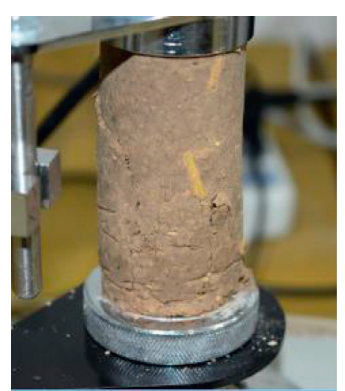

(d)

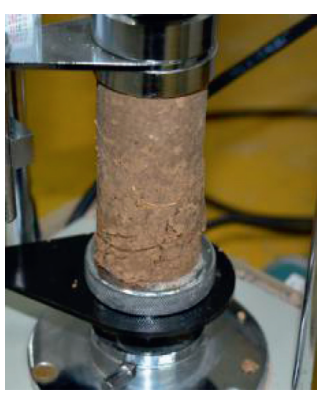

(e)

FIGURE 9: Effect of wheat straw content on failure mechanism of specimens. (a) $0 \%$ wheat straw content. (b) $0.10 \%$ wheat straw content. (c) $0.15 \%$ wheat straw content. (d) $0.20 \%$ wheat straw content. (e) $0.25 \%$ wheat straw content. 


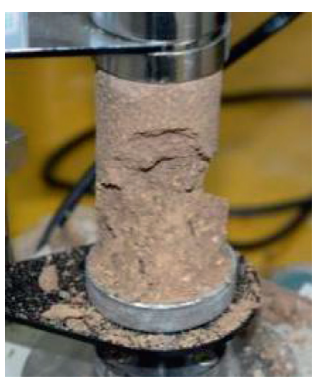

(a)

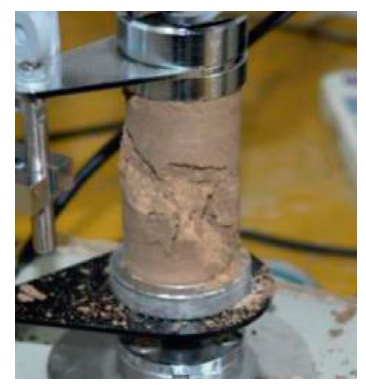

(b)

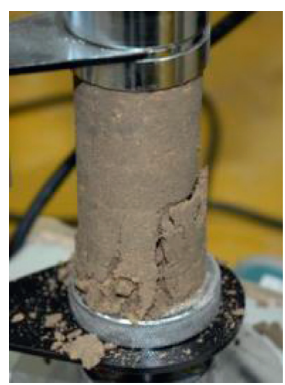

(c)

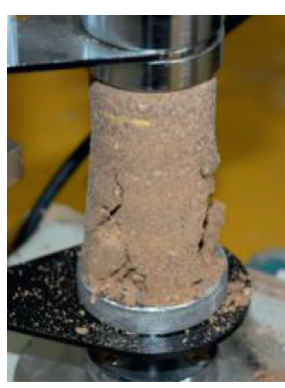

(d)

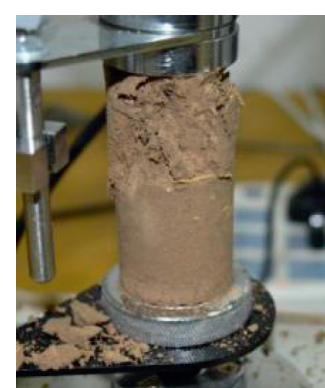

(e)

FIGURE 10: Effect of wheat straw content on failure mechanism of specimens mixed with $6 \%$ cement content. (a) $0 \%$ wheat straw content; (b) $0.10 \%$ wheat straw content; (c) $0.15 \%$ wheat straw content; (d) $0.20 \%$ wheat straw content; (e) $0.25 \%$ wheat straw content.

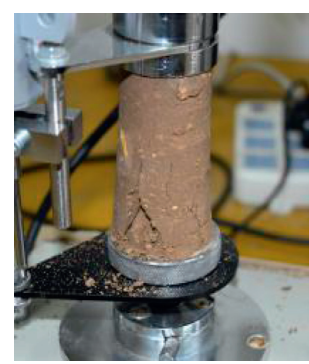

(a)

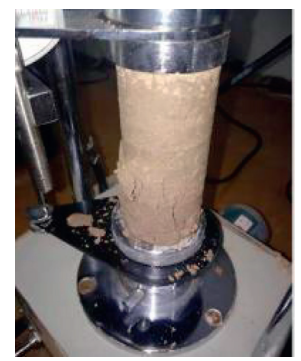

(b)

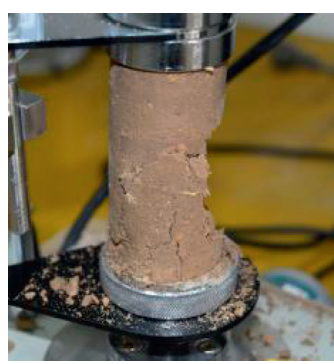

(c)

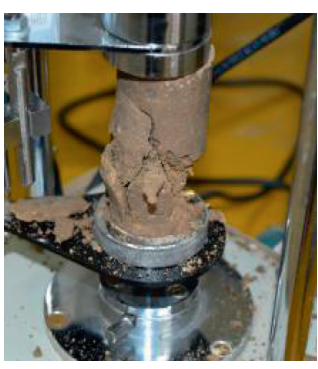

(d)

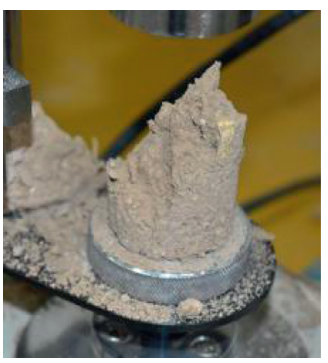

(e)

FIGURE 11: Effect of curing period on failure mechanism of specimens mixed with $3 \%$ cement content and $0.1 \%$ wheat straw content. (a) 3 days; (b) 7 days; (c) 14 days; (d) 28 days; (e) 56 days.

mixed with $0.2 \%$ wheat straw content and different cement content is shown in Figures 13(a)-13(d).

In Figures 13(a)-13(d), the curve fitting can be expressed by the following expression:

$$
p=\left(p_{\mathrm{u}}-p_{0}\right) \cdot\left(1-e^{(-\alpha \cdot t)}\right)+p_{0}
$$

where $p$ is unconfined compressive strength of specimens; $t$ is curing period; $p_{\mathrm{u}}$ is ultimate unconfined compressive strength; $p_{0}$ is initial unconfined compressive strength; $\alpha$ is the coefficient related to the shape of curves.

In equation (3), using fitting method, $p_{\mathrm{u}}, p_{0}$, and $\alpha$ can be obtained based on the data from Figures $12(\mathrm{a})-12(\mathrm{~d})$, as shown in Table 5.

As shown in Table 5, $\alpha$ is in the range of 0.14398 to 0.14643 , showing that the change of the value of $\alpha$ is very little. The mean value for $\alpha$ is 0.14533 . Therefore, in order to simplify equation (1), the value of $\alpha$ is replaced by 0.145 , and equation (1) can be expressed as

$$
p=\left(p_{\mathrm{u}}-p_{0}\right) \cdot\left(1-e^{(-0.145 \cdot t)}\right)+p_{0} .
$$

3.3.1. Initial Unconfined Compressive Strength, $p_{0}$. In equation (4), $p_{0}$ and $p_{\mathrm{u}}$ can also be obtained based on the data from Figures 10(a)-10(d) by fitting method, as shown in Table 6. Based on the data from Table 6, the curve fitting for the relationship between $p_{0}$ and wheat straw content for different cement content can be obtained, as shown in Figure 14.
For the curve fitting in Figures 14(a)-14(d), it can be described by the following expression:

$$
p_{0}=\eta \cdot e^{b \cdot a_{s}}+p_{0 i}
$$

where $\eta$ is the coefficient for curve growth; $a_{s}$ is wheat straw content, $\% ; b$ is the exponent; $p_{0 i}$ is initial unconfined compressive strength only related to cement content. Based on the data from Table $6, \eta, b$, and $p_{0 i}$ in equation (5) can be obtained by fitting method, as shown in Table 7.

As can be seen from Table 7, the change of $\eta$ is very little and the mean value for $\eta$ is 0.0017 . Therefore, equation (5) can be simplified and expressed as

$$
p_{0}=0.0017 \cdot e^{b \cdot a_{s}}+p_{0 i} .
$$

Similarly, based on the data from Table 6 and equation (6), $b$ and $p_{0 i}$ can be obtained by fitting method, as shown in Table 8.

As shown in Table 8 , the change of $b$ is also very little and the mean value for $b$ is 9.356 . Therefore, in order to simplify equation (6), $b$ is replaced by 9.356 in equation (6), and then it is expressed as

$$
p_{0}=0.0017 \cdot e^{9.356 \cdot a_{s}}+p_{0 i} .
$$

Moreover, as can be seen from Table $8, p_{0 i}$ is related to cement content. Based on the data from Table 8, the relationship between $p_{0 i}$ and cement content can also be obtained, as shown in Figure 15. 


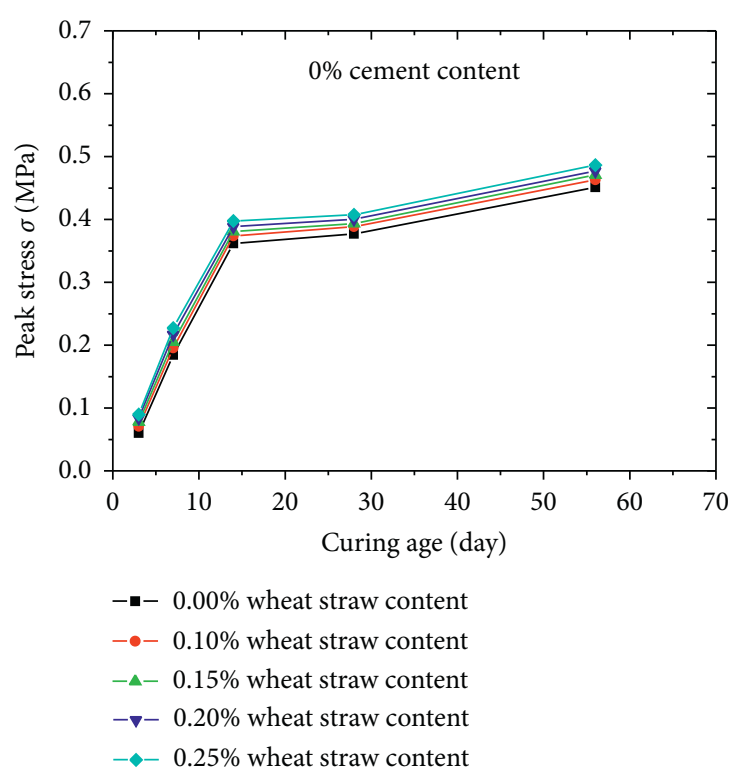

(a)

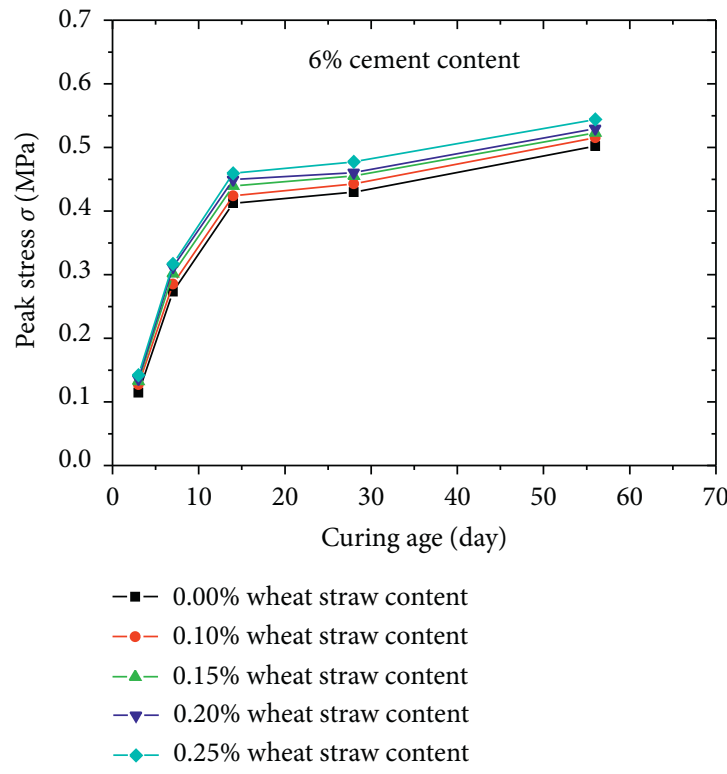

(c)

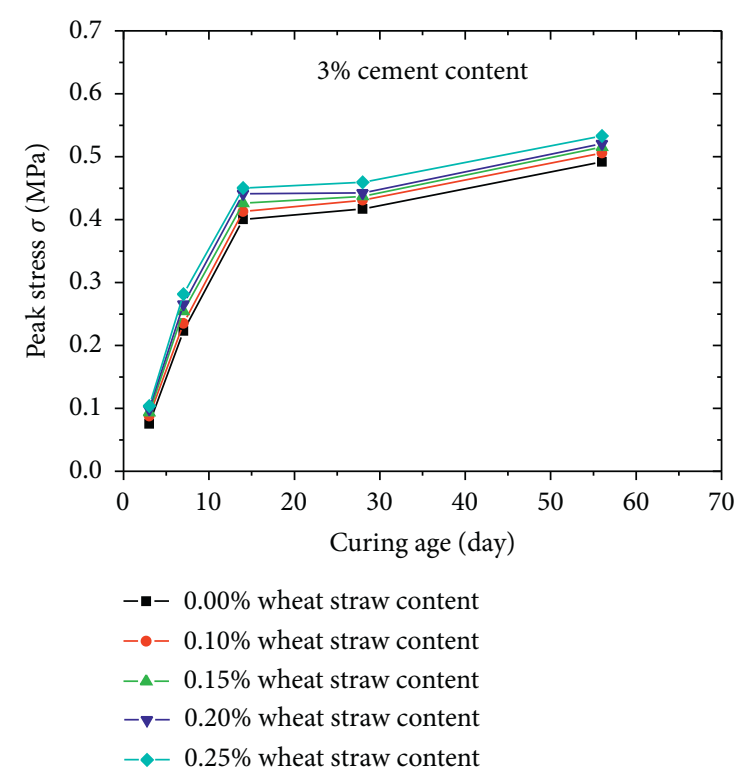

(b)

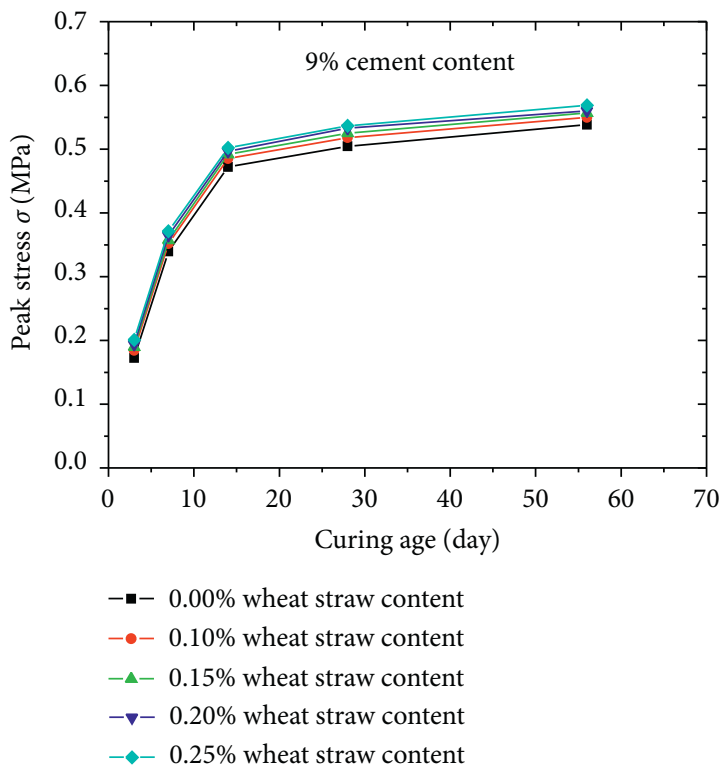

(d)

FIGURE 12: Effect of curing periods on unconfined compressive strength of specimens mixed with wheat straws and different cement content. (a) $0 \%$ cement content. (b) $3 \%$ cement content. (c) $6 \%$ cement content. (d) $9 \%$ cement content.

The curve fitting for relationship between $p_{0 i}$ and cement content in Figure 15 can be expressed as

$$
p_{0 i}=0.08014+0.01086 \cdot a_{c}
$$

where $a_{\mathrm{c}}$ is cement content, \%. Therefore, equation (7) can be expressed as

$$
p_{0}=0.0017 \cdot e^{9.356 \cdot a_{s}}+0.01086 \cdot a_{c}+0.08014
$$

3.3.2. Ultimate Unconfined Compressive Strength, $p_{u}$. In this section, equation (4) is also used to determine the value of $p_{\mathrm{u}}$. However, in equation (4), $p_{0}$ can be obtained from equation (9) according to the cement content and wheat straw content. Furthermore, based on the data from Figures 12(a)-12(d), $p_{\mathrm{u}}$ can be obtained with equation (3), as shown in Table 9.

For the curve fitting in Figure 16, it can be described by the following expression:

$$
p_{\mathrm{u}}=a \cdot e^{\left(-\varsigma \cdot a_{s}\right)}+p_{\mathrm{u} i}
$$

where $a$ is the coefficient related to curve growth; $a_{s}$ is wheat straw content, $\% ; b$ is the exponent; $p_{\mathrm{u} i}$ is initial ultimate unconfined compressive strength of specimens only related to cement content. Similarly, $a, \varsigma$, and $p_{\mathrm{u} i}$ in equation (10) can be obtained by fitting method based on the data from Table 9, as shown in Table 10. 


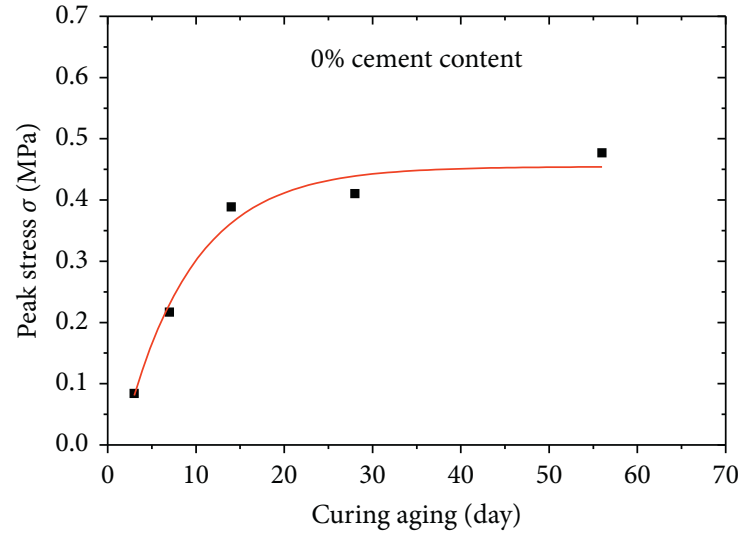

(a)

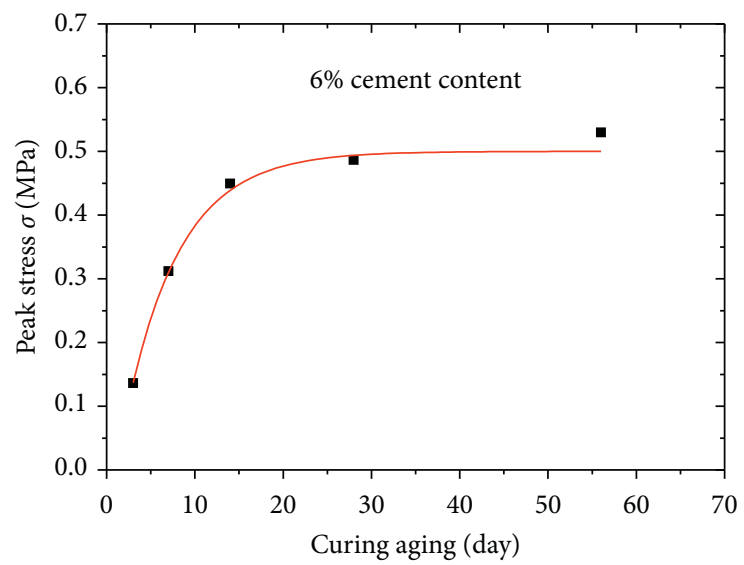

(c)

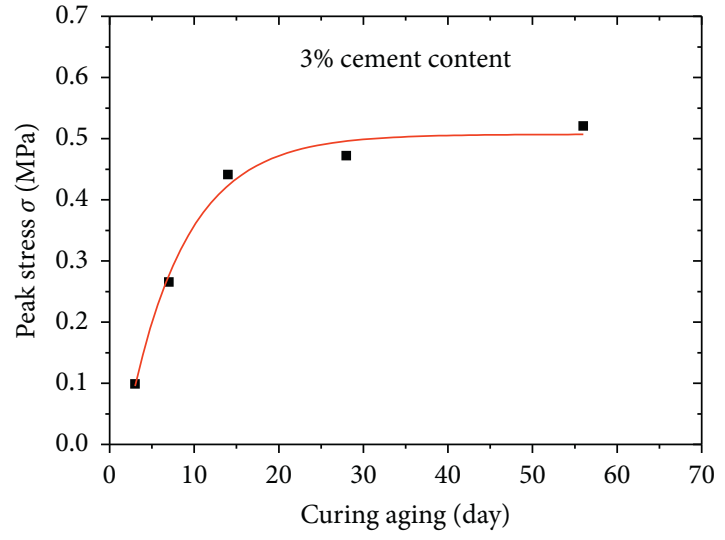

(b)

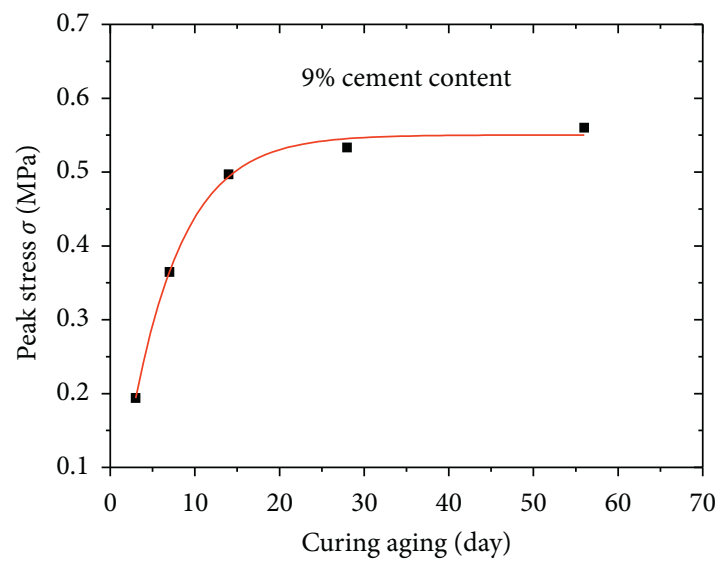

(d)

Figure 13: Curve fitting for the relationship between curing periods and unconfined compressive strength of specimens mixed with $0.2 \%$ wheat straw and different cement content. (a) $0 \%$ cement content. (b) $3 \%$ cement content. (c) $6 \%$ cement content. (d) $9 \%$ cement content.

TABle 5: $p_{\mathrm{u}}, p_{0}$, and $\alpha$ in equation (3) obtained by fitting method.

\begin{tabular}{|c|c|c|c|c|c|}
\hline Cement content $(\%)$ & Wheat straw content (\%) & $A$ & $p_{\mathrm{u}}$ & $p_{0}$ & Correlation coefficient $(R)$ \\
\hline \multirow{5}{*}{0} & 0.00 & 0.14588 & 0.43154 & 0.09152 & 0.98592 \\
\hline & 0.10 & 0.14516 & 0.44304 & 0.09313 & 0.98594 \\
\hline & 0.15 & 0.14618 & 0.44932 & 0.09624 & 0.98513 \\
\hline & 0.20 & 0.14544 & 0.45447 & 0.10006 & 0.98573 \\
\hline & 0.25 & 0.14475 & 0.46229 & 0.10691 & 0.98532 \\
\hline \multirow{5}{*}{3} & 0.00 & 0.14579 & 0.58251 & 0.12124 & 0.98826 \\
\hline & 0.10 & 0.14551 & 0.58510 & 0.12383 & 0.98837 \\
\hline & 0.15 & 0.14540 & 0.58738 & 0.12611 & 0.98756 \\
\hline & 0.20 & 0.14464 & 0.59306 & 0.13179 & 0.98620 \\
\hline & 0.25 & 0.14476 & 0.59871 & 0.13744 & 0.98922 \\
\hline \multirow{5}{*}{6} & 0.00 & 0.14398 & 0.73439 & 0.15303 & 0.98871 \\
\hline & 0.10 & 0.14613 & 0.73703 & 0.15567 & 0.98887 \\
\hline & 0.15 & 0.14558 & 0.74029 & 0.15893 & 0.98998 \\
\hline & 0.20 & 0.14623 & 0.74398 & 0.16262 & 0.98928 \\
\hline & 0.25 & 0.14489 & 0.74994 & 0.16858 & 0.99096 \\
\hline \multirow{5}{*}{9} & 0.00 & 0.14483 & 0.89900 & 0.18327 & 0.99765 \\
\hline & 0.10 & 0.14643 & 0.90140 & 0.18567 & 0.99796 \\
\hline & 0.15 & 0.14568 & 0.90410 & 0.18837 & 0.99796 \\
\hline & 0.20 & 0.14456 & 0.90841 & 0.19268 & 0.99864 \\
\hline & 0.25 & 0.14483 & 0.91405 & 0.19832 & 0.99801 \\
\hline
\end{tabular}


TABLE 6: $p_{0}$ and $p_{\mathrm{u}}$ in equation (4) obtained by fitting method.

\begin{tabular}{|c|c|c|c|c|c|}
\hline Cement content (\%) & Wheat straw content (\%) & $\alpha$ & $p_{\mathrm{u}}$ & $p_{0}$ & Correlation coefficient (R) \\
\hline \multirow{5}{*}{0} & 0.00 & \multirow{5}{*}{0.145} & 0.42040 & 0.08205 & 0.98389 \\
\hline & 0.10 & & 0.43203 & 0.08498 & 0.98396 \\
\hline & 0.15 & & 0.43892 & 0.08708 & 0.98338 \\
\hline & 0.20 & & 0.44639 & 0.09132 & 0.98464 \\
\hline & 0.25 & & 0.45536 & 0.09759 & 0.98451 \\
\hline \multirow{5}{*}{3} & 0.00 & \multirow{5}{*}{0.145} & 0.56306 & 0.11459 & 0.98765 \\
\hline & 0.10 & & 0.57668 & 0.11623 & 0.98763 \\
\hline & 0.15 & & 0.58741 & 0.11906 & 0.98752 \\
\hline & 0.20 & & 0.59589 & 0.12309 & 0.98607 \\
\hline & 0.25 & & 0.61033 & 0.12917 & 0.98894 \\
\hline \multirow{5}{*}{6} & 0.00 & \multirow{5}{*}{0.145} & 0.75501 & 0.14632 & 0.98870 \\
\hline & 0.10 & & 0.75883 & 0.14825 & 0.98885 \\
\hline & 0.15 & & 0.76059 & 0.15161 & 0.98966 \\
\hline & 0.20 & & 0.76642 & 0.15566 & 0.98839 \\
\hline & 0.25 & & 0.78146 & 0.16166 & 0.99062 \\
\hline \multirow{5}{*}{9} & 0.00 & \multirow{5}{*}{0.145} & 0.93233 & 0.18034 & 0.99679 \\
\hline & 0.10 & & 0.94507 & 0.18203 & 0.99703 \\
\hline & 0.15 & & 0.95207 & 0.18589 & 0.99711 \\
\hline & 0.20 & & 0.95780 & 0.18931 & 0.99748 \\
\hline & 0.25 & & 0.96357 & 0.19594 & 0.99705 \\
\hline
\end{tabular}

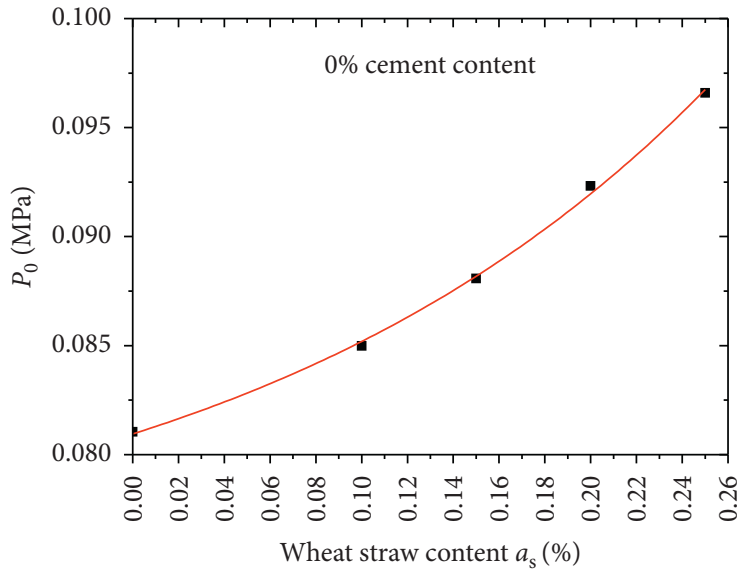

(a)

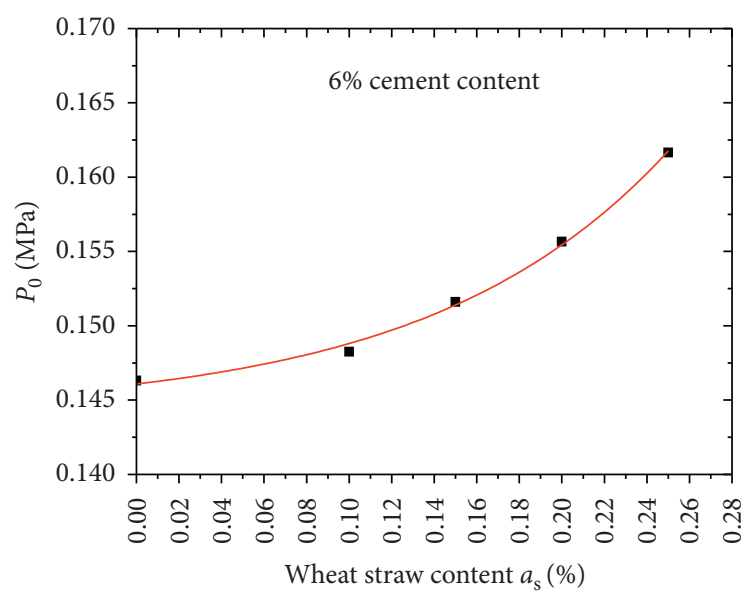

(c)

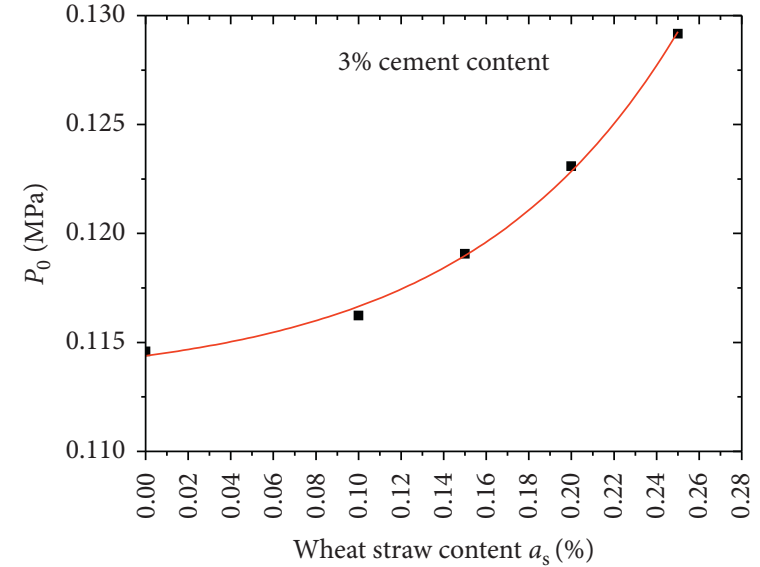

(b)

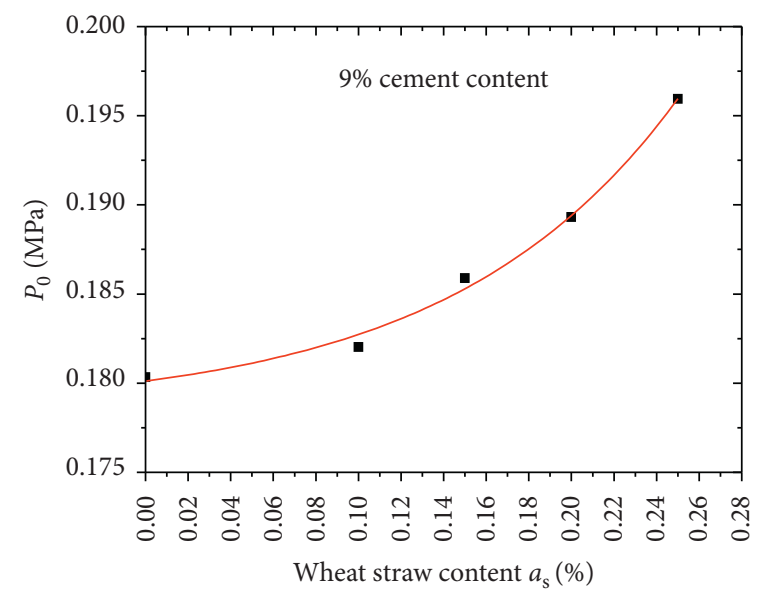

(d)

Figure 14: Curve fitting for the relationship between $p_{0}$ and wheat straw content for different cement content. (a) $0 \%$ cement content. (b) $3 \%$ cement content. (c) $6 \%$ cement content. (d) $9 \%$ cement content. 
TABLe 7: $\eta, b$, and $p_{0 i}$ in equation (5) obtained by fitting method.

\begin{tabular}{lcccc}
\hline Cement content $(\%)$ & $\mathrm{H}$ & $b$ & $p_{0 i}$ & Correlation coefficient $(R)$ \\
\hline 0 & 0.00176 & 8.92416 & 0.08035 & 0.99965 \\
3 & 0.00159 & 9.10512 & 0.11308 & 0.99895 \\
6 & 0.00188 & 9.38257 & 0.14420 & 0.99844 \\
9 & 0.00167 & 10.08636 & 0.17843 & 0.99709 \\
\hline
\end{tabular}

TABLE 8: $b$ and $p_{0 i}$ in equation (6) obtained by fitting method.

\begin{tabular}{lccc}
\hline Cement content & $b$ & $p_{0 i}$ & Correlation coefficient $(\mathrm{R})$ \\
\hline 0 & 9.34882 & 0.08053 & 0.99962 \\
3 & 9.24118 & 0.11252 & 0.99858 \\
6 & 9.39121 & 0.14456 & 0.99832 \\
9 & 9.44322 & 0.17848 & 0.99709 \\
\hline
\end{tabular}

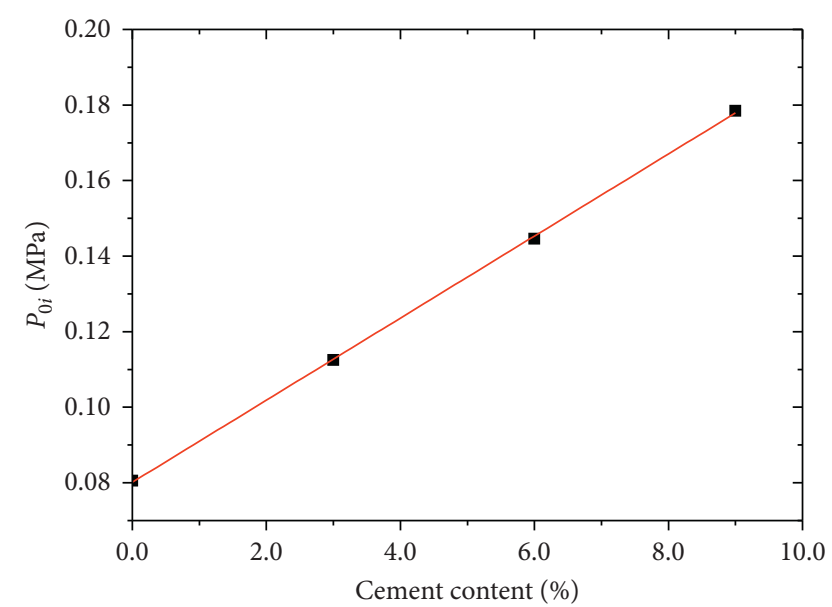

Figure 15: Curve fitting for the relationship between $p_{0 i}$ and cement content.

TABLe 9: $p_{\mathrm{u}}$ in equation (3) obtained with equation (4).

\begin{tabular}{|c|c|c|c|}
\hline Cement content (\%) & $\begin{array}{c}\text { Wheat straw content } \\
(\%)\end{array}$ & $\alpha$ & $p_{\mathrm{u}}$ \\
\hline \multirow{5}{*}{0} & 0.00 & \multirow{5}{*}{0.145} & 0.42179 \\
\hline & 0.10 & & 0.43434 \\
\hline & 0.15 & & 0.43685 \\
\hline & 0.20 & & 0.44085 \\
\hline & 0.25 & & 0.45725 \\
\hline \multirow{5}{*}{3} & 0.00 & \multirow{5}{*}{0.145} & 0.56437 \\
\hline & 0.10 & & 0.57692 \\
\hline & 0.15 & & 0.58943 \\
\hline & 0.20 & & 0.59343 \\
\hline & 0.25 & & 0.61983 \\
\hline \multirow{5}{*}{6} & 0.00 & \multirow{5}{*}{0.145} & 0.75695 \\
\hline & 0.10 & & 0.75950 \\
\hline & 0.15 & & 0.76201 \\
\hline & 0.20 & & 0.76601 \\
\hline & 0.25 & & 0.78241 \\
\hline \multirow{5}{*}{9} & 0.00 & \multirow{5}{*}{0.145} & 0.92953 \\
\hline & 0.10 & & 0.94208 \\
\hline & 0.15 & & 0.95459 \\
\hline & 0.20 & & 0.95859 \\
\hline & 0.25 & & 0.96499 \\
\hline
\end{tabular}

As can be seen from Table 10, $a$ is in the range of 0.00832 to 0.00861 , showing that the change of $a$ is very little. The mean value for $a$ is 0.00849 and the value of $a$ in equation (10) is replaced by 0.0085 ; then equation (10) can be expressed as

$$
p_{\mathrm{u}}=0.0085 \cdot e^{\left(-\xi \cdot a_{s}\right)}+p_{\mathrm{u} i} \cdot
$$

Then, based on equation (11) and the data in Table 9, $\varsigma$ and $p_{\mathrm{u} i}$ can be further obtained by fitting method, as shown in Table 11.

Figure 17 shows the curve fitting for the relationship between $\xi$ and cement content, and the following expression can describe the curve fitting:

$$
\xi=a_{1} \cdot e^{\left(-b_{1} \cdot a_{c}\right)}+\xi_{0}
$$

where $a_{1}$ is the coefficient related to curve growth; $a_{c}$ is cement content, $\% ; b_{1}$ is the exponent; $\xi_{0}$ is initial value of $\xi$ only related to cement content. Based on the data from Table $11, a_{1}, b_{1}$, and $\xi_{0}$ can be obtained by fitting method, which are $1.514,0.096$, and 5.002, respectively. Therefore, equation (12) can be expressed as

$$
\xi=1.514 \cdot e^{\left(-0.096 \cdot a_{c}\right)}+5.002 .
$$

Moreover, Figure 18 shows the curve fitting for the relationship between $p_{\mathrm{u} i}$ and cement content. The following expression can describe the fitting curve in Figure 18:

$$
p_{\mathrm{u} i}=0.0571 \cdot a_{c}+0.40226 \text {. }
$$

Therefore, substituting equations (13) and (14) into equation (11), it can be expressed as

$$
p_{\mathrm{u}}=0.0085 \cdot e^{\left(-\left(1.514 \cdot e^{\left(-0.096 \cdot a_{c}\right)}+5.002\right) \cdot a_{s}\right)}+0.0571 \cdot a_{c}+0.40226
$$

$p_{0}$ and $p_{\mathrm{u}}$ in equation (4) are replaced by equations (9) and (15); then equation (4) can be expressed as

$$
\begin{aligned}
p= & \left(\begin{array}{c}
0.0085 \cdot e^{\left(-\left(1.514 \cdot e^{\left(-0.096 \cdot a_{c}\right)}+5.002\right) \cdot a_{s}\right.}+0.04624 \cdot a_{c}+0.04624 \\
-0.0017 \cdot e^{9.356 \cdot a_{s}}
\end{array}\right) \\
& \cdot\left(1-e^{(-0.145 \cdot t)}\right)+0.00165 \cdot e^{9.356 \cdot a_{s}}+0.01086 \cdot a_{c}+0.08014
\end{aligned}
$$

From the published literature [16], ultimate unconfined compressive strength increased firstly with adding wheat straws; however, with further increasing of wheat straws content, the ultimate unconfined compressive strength decreased. In test, we cannot find the maximum wheat straws content, and therefore when using equation (16) to predict the ultimate unconfined compressive strength, wheat straws 


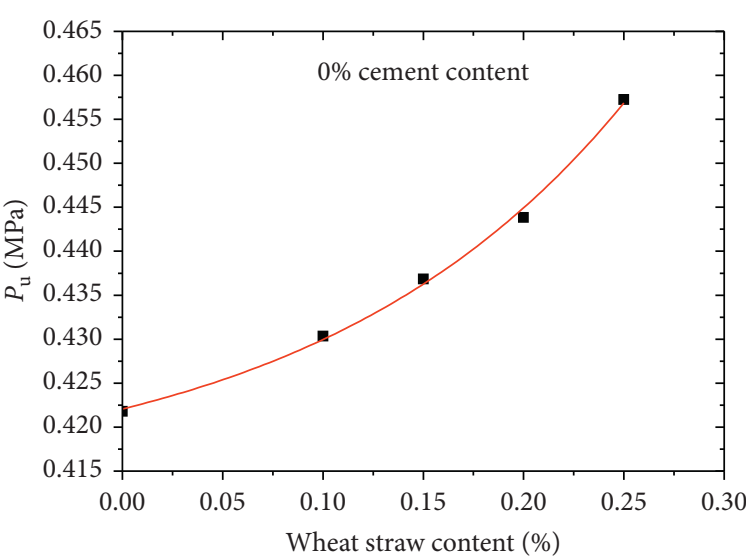

(a)

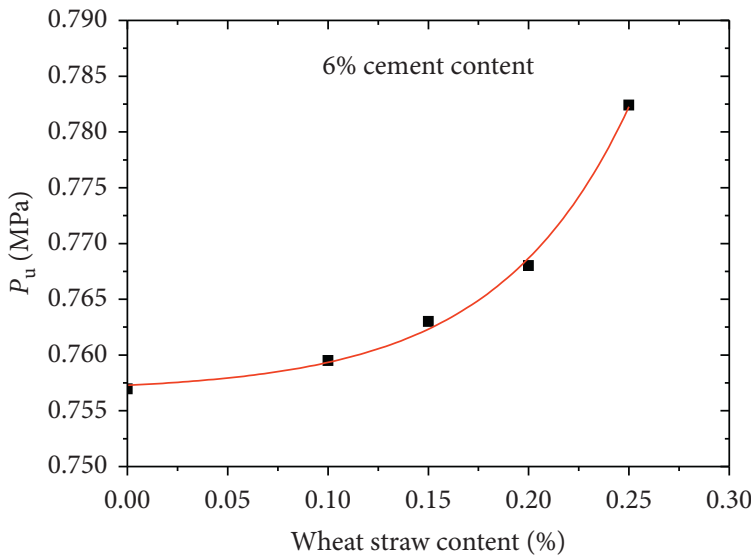

(c)

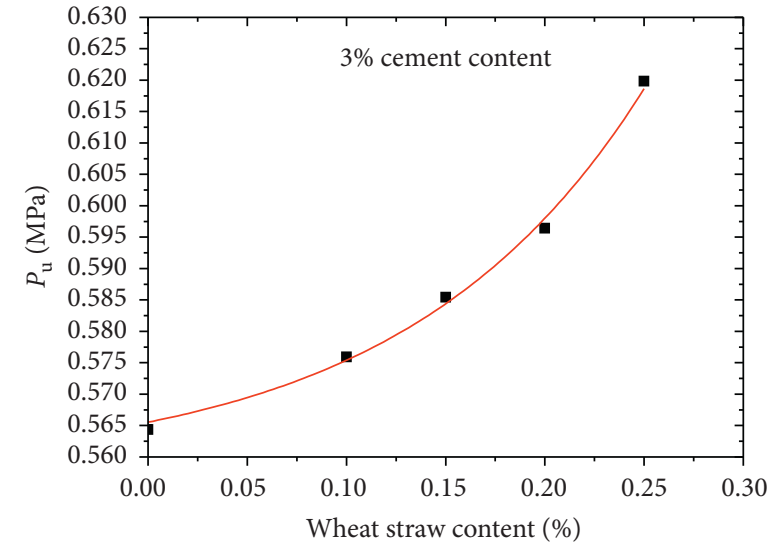

(b)

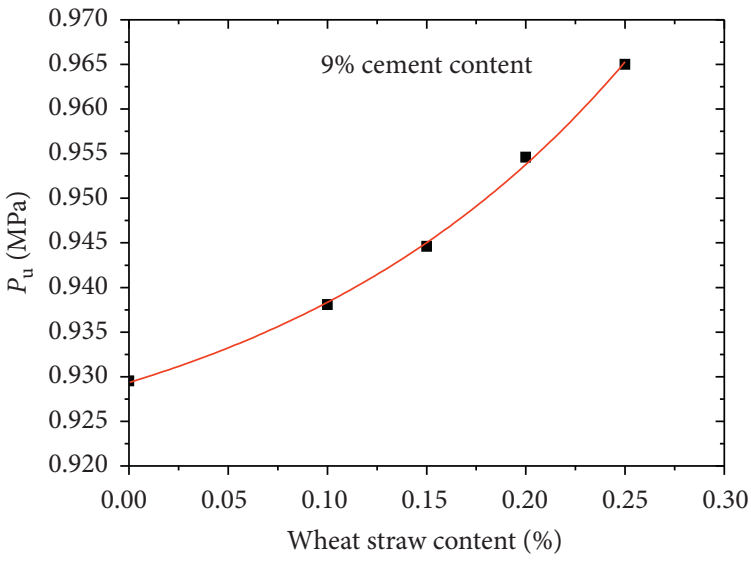

(d)

FiguRE 16: Curve fitting for the relationship between $p_{\mathrm{u}}$ and wheat straw content for different cement content. (a) $0 \%$ cement content. (b) $3 \%$ cement content. (c) $6 \%$ cement content. (d) $9 \%$ cement content.

TABLE 10: $a, \varsigma$, and $p_{\mathrm{u} i}$ in equation (10) obtained by fitting method.

\begin{tabular}{lcccc}
\hline Cement content & $a$ & $\varsigma$ & $p_{\mathrm{u} i}$ & Correlation coefficient (R) \\
\hline 0 & 0.00861 & 6.39527 & 0.41324 & 0.99870 \\
3 & 0.00832 & 6.89803 & 0.55693 & 0.99837 \\
6 & 0.00857 & 7.45161 & 0.75670 & 0.99865 \\
9 & 0.00848 & 8.32193 & 0.91686 & 0.99934 \\
\hline
\end{tabular}

TABLE 11: $\varsigma$ and $p_{\mathrm{u} i}$ in equation (11) obtained by fitting method.

\begin{tabular}{lcccc}
\hline Cement content (\%) & $a$ & $\varsigma$ & $p_{\mathrm{u} i}$ & Correlation coefficient (R) \\
\hline 0 & & 6.51373 & 0.41364 & 0.99869 \\
3 & & 7.02611 & 0.55628 & 0.99835 \\
6 & 0.0085 & 7.68670 & 0.74533 & 0.95976 \\
9 & & 8.58824 & 0.92165 & 0.99841 \\
\hline
\end{tabular}

content cannot exceed $0.25 \%$ by weight of saline-alkaline soils. In addition, when cement content in specimens is greater than $9 \%$ by weight of saline-alkaline soils, we cannot perform a series of tests to obtain the influence of cement content on ultimate unconfined compressive strength, and therefore in the application of equation (16), cement content should be less than 9\%. Moreover, for equation (16) derived from the test on specimens with optimum water content, when using it to predict the ultimate unconfined compressive strength for specimens, the range of optimum water content for specimens should fall into $12.7 \% \sim 14.5 \%$ by weight of saline-alkaline soils. 


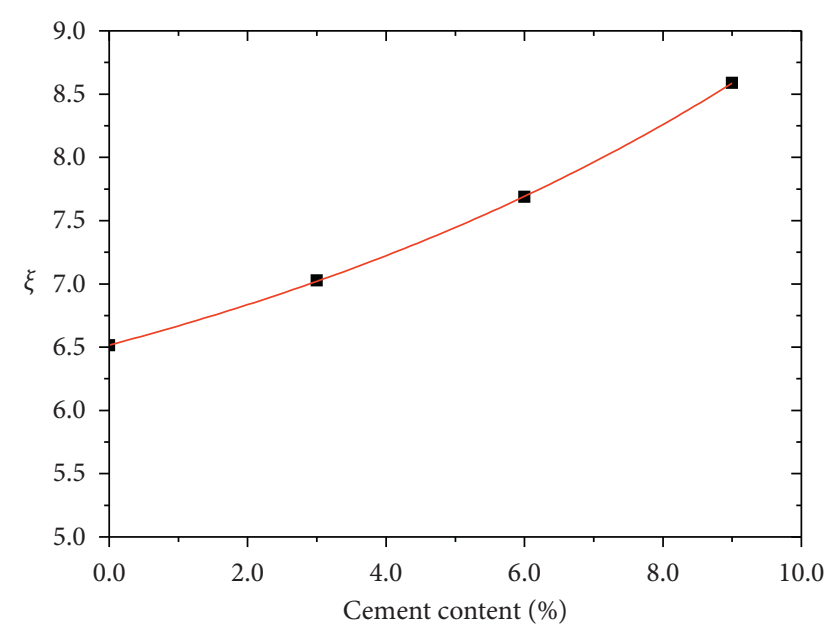

FIGURE 17: Curve fitting for the relationship between $\xi$ and cement content.

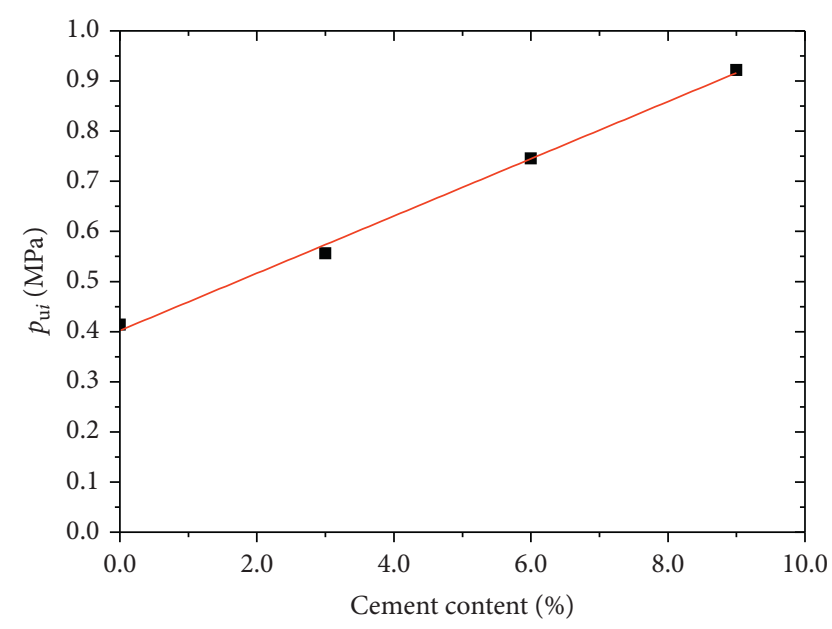

Figure 18: Curve fitting for the relationship between $p_{\mathrm{u} i}$ and cement content.

3.4. Validity of Derived Equation (16) for Unconfined Compressive Strength of Specimens. In order to obtain the reliability of derived equation (16) for unconfined compressive strength of specimens, the results from derived equation (16) should be compared with those from tests. Based on equation (16), unconfined compressive strength of specimens mixed with $6 \%$ cement content and $0.2 \%$ wheat straw content for different curing periods can be obtained, as shown in Table 12. In addition, test results for unconfined compressive strength of specimens mixed with $6 \%$ cement content and $0.2 \%$ wheat straw content for different curing periods are also shown in Table 12.

As can be seen from Table 12, most of the deviation for unconfined compression strength falls in the range of $26.0 \% \sim 30.0 \%$ and the maximum deviation for unconfined compression strength can reach $31.6 \%$ when curing period is 3 days. Therefore, compared with the test results, the accuracy of results from the derived equation (16) is not very high, also indicating that equation (16) is only applicable to the approximate evaluation of unconfined compression
TABLE 12: Unconfined compression strength obtained from test and calculated value by equation (16).

\begin{tabular}{lccc}
\hline $\begin{array}{l}\text { Curing } \\
\text { days }\end{array}$ & $\begin{array}{c}\text { Calculated value } \\
(\mathrm{MPa})\end{array}$ & $\begin{array}{c}\text { Test result } \\
(\mathrm{MPa})\end{array}$ & $\begin{array}{c}\text { Deviation } \\
(\%)\end{array}$ \\
\hline 3 & 0.179 & 0.136 & 31.6 \\
7 & 0.398 & 0.312 & 27.6 \\
14 & 0.581 & 0.449 & 29.4 \\
28 & 0.582 & 0.461 & 26.2 \\
56 & 0.681 & 0.529 & 28.6 \\
\hline
\end{tabular}

strength of saline-alkaline soils. In this paper, we only compare the test result for specimens with combination of wheat straw content and cement content already used in the current study. When using equation (16) to predict the unconfined compression strength of specimens with another combination of wheat straw content and cement content other than what had been already used in the current study, specimens should be in the state of maximum density; therefore compaction tests should be firstly carried out to obtain the optimal moisture content of the specimens.

\section{Conclusions}

In this study, a series of tests are conducted to study the effects of wheat straw and cement on the unconfined compression strength of specimens. The effect of wheat straw and cement inclusions and curing periods on unconfined compression strength is determined. The following conclusions are derived from these tests.

The inclusion of wheat straw within saline-alkaline soils and saline-alkaline soils mixed with cement causes an increase in unconfined compression strength. Increasing wheat straw content can increase the peak axial stress and weaken the brittle behavior of saline-alkaline soils mixed with cement. Moreover, unconfined compression strength of specimens increases with increasing curing periods. It is known that the interface roughness for wheat straw plays an important role in reinforcing the soil. Although it is an important subject, no attempt has yet been made to determine the optimum degree of the interface roughness. In addition, based on the data obtained from unconfined compression strength test, a formula for predicting the unconfined compression strength of specimens related to cement content, wheat straw content, curing periods, and so forth is put forward. Compared with test results, equation (16) is only applicable to the approximate evaluation of unconfined compression strength of specimens.

In addition, in the present study, we cannot obtain the influence of wheat straw content greater than $0.25 \%$ and/or cement content greater than $9 \%$ on unconfined compression strength of specimens of specimens. Therefore, the application scope of equation (16) is limited. If more test results of unconfined compression strength of specimens mixed with wheat straw content greater than $0.25 \%$ and/or cement content greater than $9 \%$ are obtained, the application of equation (16) will be more extensive in predicting the unconfined compression strength of specimens with optimal moisture content. Moreover, only unconfined compression 
strength tests have been conducted on specimens mixed with wheat straw and cement. Therefore, investigations should be carried out further through other strength tests like direct shear tests, triaxial shear tests, and so forth to study the influence of wheat straw on strength of specimens.

\section{Data Availability}

The data used to support the findings of this study are included within the article.

\section{Conflicts of Interest}

The authors declare no conflicts of interest with respect to the research, authorship, and/or publication of this article.

\section{Acknowledgments}

This work was financially supported by National Natural Science Foundation of China (Grant no. 51908430), Doctoral Scientific Fund Project of Weifang University (Grant no. 2017BS14), and Science and Technology Project of HighTech Zone in Weifang (Grant no. 2019KJHM09).

\section{References}

[1] R. L. Michalowski and J. Čermák, "Triaxial compression of sand reinforced with fibers," Journal of Geotechnical and Geoenvironmental Engineering, vol. 129, no. 2, pp. 125-136, 2003.

[2] T. Yetimoglu, M. Inanir, and O. Esatinanir, "A study on bearing capacity of randomly distributed fiber-reinforced sand fills overlying soft clay," Geotextiles and Geomembranes, vol. 23, no. 2, pp. 174-183, 2005.

[3] T. Park and S. Tan, "Enhanced performance of reinforced soil walls by the inclusion of short fiber," Geotextiles and Geomembranes, vol. 23, no. 4, pp. 348-361, 2005.

[4] C. Tang, B. Shi, W. Gao, F. Chen, and Y. Cai, "Strength and mechanical behavior of short polypropylene fiber reinforced and cement stabilized clayey soil," Geotextiles and Geomembranes, vol. 25, no. 3, pp. 194-202, 2007.

[5] S. Salah, N. Shadi, and F. Fadi, "Shear strength of fiberreinforced sands," Journal of Geotechnical and Geoenvironmental Engineering, vol. 136, no. 3, pp. 490-499, 2010.

[6] G. A. Santiago, C. Franco, N. C. Consoli, and V. R. Botaro, "Study of mechanical behavior of a sand soil reinforced with curaua treated fibers with asphalt," Materials Science Forum, vol. 730-732, pp. 319-324, 2012.

[7] J. Prabakar and R. S. Sridhar, "Effect of random inclusion of sisal fibre on strength behaviour of soil," Construction and Building Materials, vol. 16, no. 2, pp. 123-131, 2002.

[8] C. Mahipal Singh, M. Satyendra, and M. Bijayananda, "Performance evaluation of silty sand subgrade reinforced with fly ash and fibre," Geotextiles and Geomembranes, vol. 26, no. 5, pp. 429-435, 2008.

[9] M. Bouhicha, F. Aouissi, and S. Kenai, "Performance of composite soil reinforced with barley straw," Cement and Concrete Composites, vol. 27, no. 5, pp. 617-621, 2005.

[10] N. C. Consoli, M. D. T. Casagrande, P. D. M. Prietto, and A. n. Thomé, "Plate load test on fiber-reinforced soil," Journal of Geotechnical and Geoenvironmental Engineering, vol. 129, no. 10, pp. 951-955, 2003.
[11] J. Yao, Experimental Study on Strength Characteristics of Wheat Straw Reinforced soil, Chang'an University, Xi'an, China, 2017.

[12] A. Adili, A. Rafig, S. Giovanni et al., "Strength of soil reinforced with fiber materials (papyrus)," Soil Mechanics and Foundation Engineering, vol. 48, no. 6, pp. 241-247, 2012.

[13] Y. L. Qian, "Experimentresearch of mechanical properties of improved saline soil," Geotechnical Investigation and Surveying, vol. 5, pp. 1-4, 2003.

[14] X. S. Wang, H. Q. Zhang, and M. Xue, "Road disease and treatment in saline soil area," Journal of Tongji University, vol. 31, no. 10, pp. 1178-1182, 2003.

[15] Q. L. Wang, Y. Chao, Y. F. Liu et al., "Mechanical properties of saline soil under the influence of different factors," Fresenius Environmental Bulletin, vol. 28, no. 2A, pp. 1366-1373, 2019.

[16] L. Wei, S. X. Chai, H. Z. Cai et al., "Research on tensility of wheat straw for reinforced material," Rock \& Soil Mechanics, vol. 31, no. 1, pp. 128-132, 2010.

[17] L. Wei, S. X. Chai, H. Z. Cai et al., "Physical and mechanical properties of wheat straw and unconfined compressive strength of reinforced inshore saline soil with wheat straw," China Civil Engineering Journal, vol. 43, no. 3, pp. 93-98, 2010.

[18] M. Li, S. X. Chai, H. P. Du et al., "Reasonable reinforcement position and shear strength model of reinforced saline soil with wheat straw and lime," Chinese Jourhal of Rock Mechanics and Engineering, vol. 29, no. sup 2, pp. 3923-3929, 2010.

[19] P. Wang, S. X. Chai, X. Y. Wang et al., "Analysis of effect factors of heavy compaction test for wheat straw-reinforced saline soil," Rock and Soil Mechanics, vol. 32, no. 2, pp. 448-452, 2011.

[20] L. Wei, S. X. Chai, H. Z. Cai et al., "Triaxial shear strength and deviatoric stress-strain of saline soils reinforced with wheat straws," China Civil Engineering Journal, vol. 45, no. 1, pp. 109-114, 2012.

[21] H. Lu, C. G. Yan, X. H. Yang et al., "Experiment on antieroding property of reinforced loess with wheat straw," Journal of Chang'an University (Natural Science Edition), vol. 37, no. 1, pp. 24-32, 2017.

[22] J. B. Hao, X. M. Wei, J. Yao et al., "Strength characteristics and mesostructure of wheat straw einforced soil," Journal of Tongji University (Natural Science), vol. 47, no. 6, pp. 764-831, 2019.

[23] GB50007-2011, Code for Design of Building foundation, Ministry of Housing and Urban-Rural Development, Beijing, China, 2012.

[24] JTG D30-2015, Specifications for Design of Highway Subgrades, China Communications Publishing \& Media Management Co., Ltd., Beijing, China, 2016.

[25] GB/T 50123-1999, Standard for Soil Test Method, Ministry of Construction, Beijing, China, 2000. 